\title{
The Role of Next-Generation Sequencing in Pharmacogenetics and Pharmacogenomics
}

\author{
Ute I. Schwarz, ${ }^{1,2}$ Markus Gulilat, ${ }^{2}$ and Richard B. Kim ${ }^{1,2}$ \\ ${ }^{1}$ Division of Clinical Pharmacology, Department of Medicine, Western University, London, Ontario N6A 5A5, \\ Canada \\ ${ }^{2}$ Department of Physiology and Pharmacology, Western University, London, Ontario N6A 5A5, Canada \\ Correspondence: ute.schwarz@lhsc.on.ca
}

\begin{abstract}
Inherited genetic variations in pharmacogenetic loci are widely acknowledged as important determinants of phenotypic differences in drug response, and may be actionable in the clinic. However, recent studies suggest that a considerable number of novel rare variants in pharmacogenes likely contribute to a still unexplained fraction of the observed interindividual variability. Next-generation sequencing (NGS) represents a rapid, relatively inexpensive, large-scale DNA sequencing technology with potential relevance as a comprehensive pharmacogenetic genotyping platform to identify genetic variation related to drug therapy. However, many obstacles remain before the clinical use of NGS-based test results, including technical challenges, functional interpretation, and strict requirements for diagnostic tests. Advanced computational analyses, high-throughput screening methodologies, and generation of shared resources with cell-based and clinical information will facilitate the integration of NGS data into candidate genotyping approaches, likely enhancing future drug phenotype predictions in patients.
\end{abstract}

nnovative and collaborative research spanning several decades have led to important new knowledge of the role of inherited genetic differences to variability in drug efficacy or toxicity (Madian et al. 2012). Individual differences in drug response may result from variation in genes controlling the pharmacokinetics (PK) of a drug (its absorption, distribution, metabolism, and excretion [ADME]) or drug targets, typically referred to as pharmacodynamics (PD). Therefore, whereas alteration in systemic drug exposure or tissue concentrations will generally lead to changes in pharmacological effects, genetic variation in drug target genes will affect drug concentration needed at target sites for optimal drug response. Hence, pharmacogenetic studies have focused on genes encoding drug-metabolizing enzymes, drug transporters, and drug targets (often referred to as pharmacogenes) involved in drug PK and PD as well as comedications and environmental factors interacting with these proteins.

\section{PHARMACOGENETICS AND CLINICALLY ACTIONABLE VARIATION}

Pharmacogenetics is known as the study of heritable variability in response to drugs concerning ADME or drug target genes, whereas pharmacogenomics is understood as a more

Editors: W. Richard McCombie, Elaine R. Mardis, James A. Knowles, and John D. McPherson

Additional Perspectives on Next-Generation Sequencing in Medicine available at www.perspectivesinmedicine.org

Copyright (C 2019 Cold Spring Harbor Laboratory Press; all rights reserved; doi: 10.1101/cshperspect.a033027

Cite this article as Cold Spring Harb Perspect Med 2019;9:a033027 
U.I. Schwarz et al.

comprehensive, genome-wide approach to drug response (Pirmohamed 2001). To date, singlenucleotide variants (SNVs) represent the most common form of protein-altering "functional variants" identified among pharmacogenes. Functional SNVs have been reported in genes of enzymes catalyzing drugs by phase I (i.e., cytochrome P450s or CYP) (Fujikura et al. 2015) or phase II metabolism (i.e., glutathione transferases [GSTs], UDP-glucuronosyltransferases [UGTs], sulfotransferases [SULTs]) (Guillemette 2003; Hayes et al. 2005; Cook et al. 2013; James and Ambadapadi 2013) as well as ATPbinding cassette $(\mathrm{ABC})$ efflux transporters, solute carriers (SLCs) (DeGorter and Kim 2009; Nies et al. 2009; Franke et al. 2010; DeGorter et al. 2012), or regulatory proteins (pregnane $\mathrm{X}$ receptor [PXR], farnesoid X receptor [FXR]) (Omiecinski et al. 2011). In addition, select drug targets such as the vitamin $\mathrm{K}$ reductase (VKORC1) or the $\beta$ adrenoreceptors 1 and 2 ( $A D R B 1$ and 2) genes are known to harbor such variation. More focused pharmacogenetic as well as genome-wide association studies (GWAS) (Daly 2010; Motsinger-Reif et al. 2013) have led to new discoveries and replication of findings relating to a number of common SNV/gene drug associations, and continue to provide new therapeutic implications, thus showing the clinical relevance of such variants. To help facilitate the implementation of these clinically "actionable" variants, the Clinical Pharmacogenetics Implementation Consortium (CPIC), a U.S.-based international consortium, provides freely accessible, peer-reviewed, evidence-based guidelines with specific recommendations to aid in the interpretation and translation of genetic test results into genotype-based drug prescribing (cpicpgx.org) (Caudle et al. 2014, 2017). Currently, there are CPIC guidelines for more than 30 drugs (33 as of September 2017), including the anticoagulant warfarin (Johnson et al. 2011, 2017) and the antiplatelet clopidogrel (Scott et al. 2011, 2013), the cholesterol-lowering agent simvastatin (Ramsey et al. 2014), the immunosuppressive thiopurines azathioprine and mercaptopurine (Relling et al. 2011, 2013), the antiviral drug abacavir (Martin et al. 2014), the gout remedy allopurinol (Saito et al. 2016), and the antiepileptic carbamazepine (Leckband et al. 2013). Moreover, many pharmacogenomic biomarkers have been incorporated in drug labels by the U.S. Food and Drug Administration (www.fda.gov/ Drugs/ScienceResearch/ucm572698.htm) and the European Medicine Agency (Ehmann et al. 2015), and several U.S. hospitals have piloted preemptive pharmacogenetic screening (Dunnenberger et al. 2015).

\section{VARIANT DISCOVERY BY DNA SEQUENCING}

Traditionally, "Sanger" sequencing has been the gold standard for determining nucleotide sequence variation since the method was discovered in 1977 (Sanger et al. 1977). This method has been applied to decode the DNA sequence of the first human genome in 2003, completed after an enormous effort over more than 10 years (International Human Genome Sequencing Consortium 2004). Next-generation sequencing (NGS) refers to a relatively new, rapid, and less costly, large-scale DNA sequencing technology that enables sequencing of the entire genome (referred to as genome-wide NGS), the exons of all genes in the genome (exome-wide NGS), or only the exons of select genes (targeted exome NGS). NGS technology follows the sequencingby-synthesis principle (reviewed elsewhere in detail in Koboldt et al. 2013; Biesecker and Green 2014). After shearing genomic DNA, the resulting millions of small DNA fragments are "read" simultaneously by synthesizing a string of complementary nucleotide bases, captured as fluorescent images. The actual nucleotide sequence is computationally inferred using these images through base-calling algorithms, resulting in short DNA sequence reads subsequently assembled and aligned to the sequence of a human reference genome. The predicted accuracy of the assembly and alignment of short reads, or in other words, the ability to identify variable DNA sites with considerable confidence (Nielsen et al. 2011), varies among different NGS methods and depends on multiple factors, including the number of reads generated 
(also depth of coverage), and will be further discussed below with respect to pharmacogenes.

\section{NEXT-GENERATION SEQUENCING TO IDENTIFY VARIATION RELATED TO DISEASE AND DRUG THERAPY}

In recent years, NGS approaches have been extensively applied at a large scale to identify and characterize potentially functional variation in human genes to more fully elucidate genetic contributions to disease as well as drugtreatment outcomes, the latter of which is of particular relevance to the emerging field of personalized or precision medicine. Large international or multicenter research initiatives have already generated extensive population resources capturing DNA sequence variation in thousands to tens of thousands of individuals, in part linked to clinical data, that are made available to the scientific community. For example, the 1000 Genomes Project (Abecasis et al. 2012) (www.internationalgenome.org/data) has thus far mapped and cataloged genetic variants across 1092 human genomes from diverse populations, whereas the National Heart, Lung, and Blood Institute (NHLBI) Exome Sequencing Project (ESP) currently provides protein-coding variant information on more than 6500 clinically well-characterized patients (Tennessen et al. 2012). The Exome Aggregation Consortium (ExAC) (Lek et al. 2016) represents an even larger resource, comprising combined exome sequencing data and their predicted pathogenicity from 60,706 individuals, and the DiscovEHR study (Dewey et al. 2016) assessed functional variants in 50,726 whole-exome sequences linked to data from electronic health records to determine a potential clinical impact.

More recently, NGS has been also explored for comprehensive profiling of pharmacogenes with relevance to drug $\mathrm{PK}$ and $\mathrm{PD}$, and initial reports suggest that this technology may represent a reliable and efficient tool to discover both common and rare genetic variation in these genes (Gordon et al. 2016; Twist et al. 2016; Han et al. 2017). Detailed assessment of the available extensive sequencing data sets in large populations suggests the abundance and poten- tial functional relevance of rare, mostly novel SNVs compared to common, previously established variants among many pharmacogenes (Nelson et al. 2012; Fujikura et al. 2015; Kozyra et al. 2017). Specifically, the recent evaluation of genetic variation in phase I and II metabolic enzymes, drug transporters, and nuclear receptors combining SNV data of the ESP (6503 individuals) and 1000 Genomes Project (1092 individuals) indicates that the vast majority of all variants in coding regions are rare ( $93 \%$; minor allele frequency $[\mathrm{MAF}]<1 \%)$ or very rare $(\sim 83 \%$; MAF $<0.01 \%)$ and mostly nonsynonymous (56\% to $65 \%$ ), with an estimated $30 \%$ to $40 \%$ of functional variability likely to be attributed to these rare variants (Fujikura et al. 2015; Kozyra et al. 2017). Similarly, a resequencing study of 202 drug target genes in 14,002 subjects revealed that more than $95 \%$ of the identified variants were rare with an MAF below $0.5 \%$, and that $90 \%$ of those had not been reported before (Nelson et al. 2012).

\section{TARGETED NGS STRATEGIES FOR RARE FUNCTIONAL VARIATION IN PHARMACOGENES}

The increasing recognition of the likely presence of novel sequence variation among pharmacogenes suggests that commonly used genotyping platforms restricted to candidate variants are inadequate for a more comprehensive determination of a person's genotype, supporting the utility of NGS methods as a more rapid, comprehensive, and cost-effective strategy for variant discovery. Despite current advances, genomewide sequencing for a large number of subjects or patients is still not feasible for most research institutions for reasons including, but not limited to, cost and time commitment to ensure sequence quality as well as requirements to data storage capacity and processing. Exomewide sequencing allows for a more focused approach restricted to protein-coding regions comprising only $1 \%$ of the human genome or about 20,000 genes ( $\mathrm{Ng}$ et al. 2009); however, functional variation in noncoding regions is missed. Alternatively, "targeted" exome capture strategies enable "deep" sequencing of a relatively 
U.I. Schwarz et al.

small number of select genes of interest $(\sim 100)$, usually at a coverage of greater than 30 -fold (also 30x), minimizing error rates and uncertainty in genotype calling, which are challenges frequently associated with short-read NGS data (Nielsen et al. 2011). In contrast to SNV candidate approaches (Johnson et al. 2012), such a strategy will provide accurate genotyping results for common, functionally established genetic variation, while also capturing those that are rare and previously unreported in clinically relevant genes. Moreover, specific noncoding regions can be targeted in regions already known to harbor functional variants, as commonly observed in genes encoding phase I and II enzymes (CYP2C19*17 [Sim et al. 2013], CYP3A5*3 [Kuehl et al. 2001], CYP3A4*22 $^{*}$ [Wang et al. 2011], and UGT1A1*28 [Bosma et al. 1995]). Hence, this approach has been of particular interest to pharmacogenetic research as well as to clinical (routine) genotyping for implementing personalized genotype-based therapies.

Targeted exome NGS (Fig. 1), usually in the form of a custom gene panel, requires the capture and enrichment of genomic regions of interest before sequencing. Multiple targetenrichment strategies can be used such as polymerase chain reaction (PCR)-based, molecular inversion probe (MIP)-based (Yoon et al. 2015), or hybrid oligonucleotide capture-based approaches (reviewed in Mamanova et al. 2010; Altmuller et al. 2014); however, performance can vary from one approach to another. Accordingly, before a broader integration of such tests for research or clinical purposes, a rigorous evaluation of each custom gene panel is required to ensure its accuracy in variant and genotype calling, including validation of the optimal probe design with subsequent performance validation to ensure mapping of reads to the intended locations, even sequence coverage across target regions as well as reproducibility of the results (Mamanova et al. 2010). Recently, several custom capture-based pharmacogenetic panels have been developed comprising established ADME and drug target genes. The NGS-based platform PGRNseq has been generated for 82 pharmacogenes, and was validated in almost
300 individuals as a multicenter effort among members of the Pharmacogenomics Research Network (PGRN) together with various medical institutions in the United States (Gordon et al. 2016). In conjunction with the electronic Medical Records and Genomics (eMERGE) network, more than 5000 patients were subsequently sequenced through PGRNseq and variants, many of them identified as clinically actionable by CPIC, linked to electronic health records (eMERGE-PGx) (Rasmussen-Torvik et al. 2014; Bush et al. 2016). The resulting data will be integrated in a web-based research tool to aid the discovery of rare, clinically relevant SNVs and to pilot the integration of preemptive sequencing for therapeutic decision making in the clinical setting. Using different capture techniques, another research group from several Korean universities created and validated two target NGS panels in sets of 74 or $114 \mathrm{PK}$ and $\mathrm{PD}$ genes among 376 individuals called ADME-PGx and extended ADME-PGx, respectively. These panels were also intended to serve as a diagnostic tool for the fast and unbiased discovery of rare, potential functional variation among patients. Last, our group has designed and evaluated a targeted NGS-sequencing panel termed PGxSeq in 70 patients, involving 100 pharmacogenes, also including 14 known functional promoter or intronic SNPs with established functional relevance with similar research goals (unpublished data).

\section{TECHNICAL LIMITATIONS OF PHARMACOGENETIC NGS PLATFORMS}

Several technology-inherent limitations are debated in the literature that relate to the shortread-based nature of the NGS process causing suboptimal sequence coverage and mapping quality, thus increasing the risk of inaccurate variant and genotype calls (Nielsen et al. 2011; Drogemoller et al. 2013; Vanakker and De Paepe 2013; Lauschke and Ingelman-Sundberg 2016). First, a high degree of homology among genetic loci can lead to inappropriate capture or wrongful alignment of sequence reads to the reference genome and, therefore, false-positive or false-negative errors (recently assessed by 

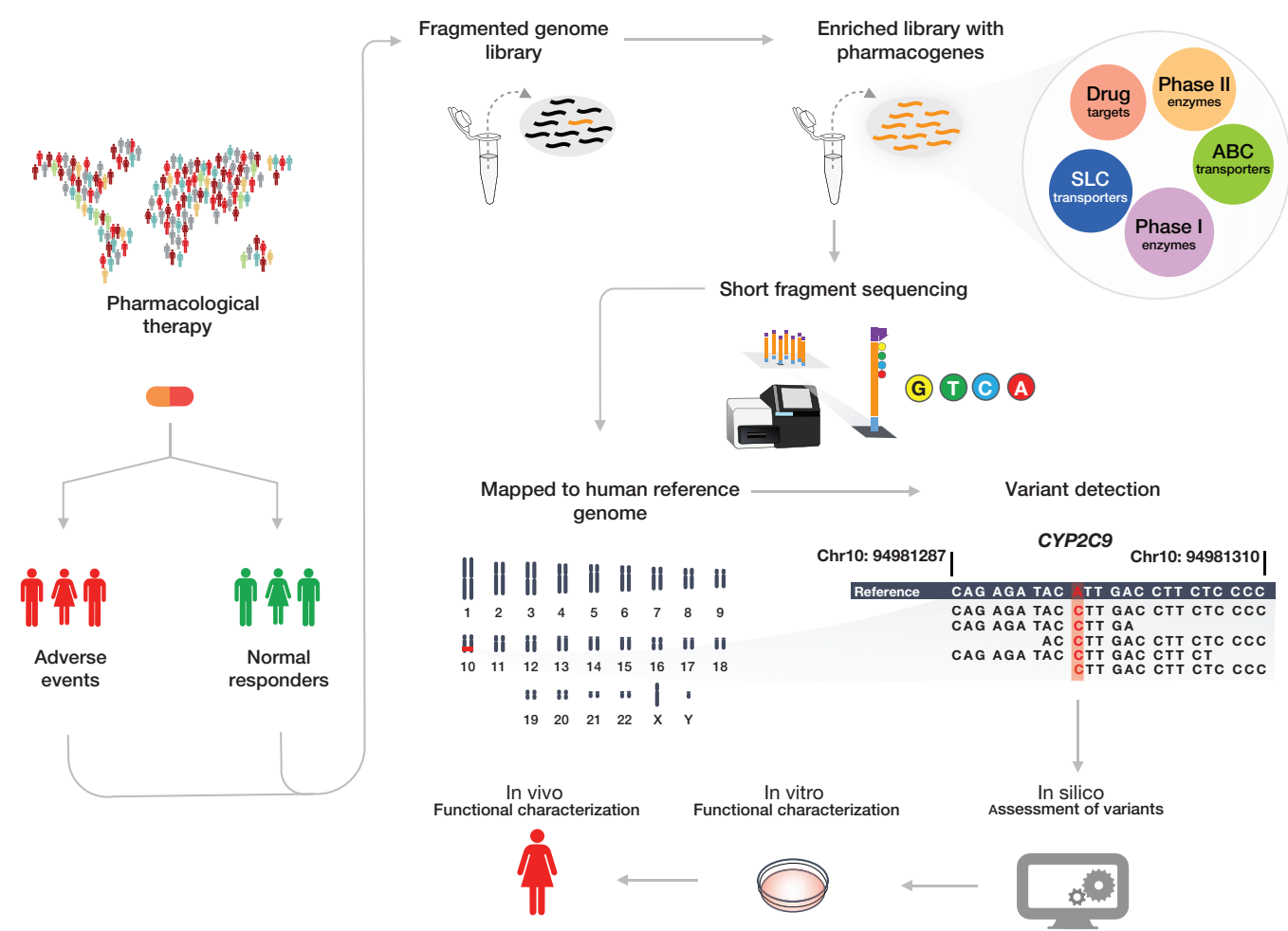

Figure 1. Schematics showing the iterative process of identification and validation of pharmacogenetic variants. SLC, Solute carrier; ABC, ATP-binding cassette.

Drogemoller et al. 2013; Mandelker et al. 2016). Regions of high homology can be found within a specific gene (between its exons) among different genes or in the case of nearby homologous nonfunctional pseudogenes. Recently, a total of 11,216 unique pseudogenes were identified in the human genome (Pei et al. 2012), indicating the considerable potential for erroneous genotype detection. It has been estimated that more than $12 \%$ of the human exome contains "difficult or unable to be analyzed" regions for NGS because of highly homologous genes (Mandelker et al. 2016). Whereas particularly concerning for genes comprising variants that are likely to predict disease risk in patients during diagnostic testing, high-sequence similarity is also observed among pharmacogenes (Mandelker et al. 2016), particularly within gene families of CYP (CYP Allele Nomenclature; www .pharmvar.org) (Nelson et al. 2004), SULT (Blanchard et al. 2004), and UGT enzymes (UGT nomenclature; www.pharmacogenomics .pha.ulaval.ca/cms/ugt_alleles) (Mackenzie et al. 1997), thus creating uncertainty concerning the reliability of genotype-based phenotype predictions or drug dose recommendations for the patient. Specifically, at least 55\% identity in the amino acid sequence exists among members of CYP subfamilies (Gonzalez 1988; Nelson et al. 1996), and, in some cases, sequence similarity of more than $90 \%$ has been reported (i.e., CYP2C9 and CYP2C19 [Nelson et al. 2004]). Second, highly polymorphic genes with complex structural variations are recognized to be challenging such as CYP2D6 (Gaedigk 2013), CYP2A6 (Rao et al. 2000), or the human leukocyte antigen (HLA) genes, encoding the major histocompatibility complex (MHC) proteins in humans (The MHC Sequencing Consortium 1999) because they are prone to potential misalignments, whereas high GC content and regions of low complexity may affect the accessibility of gene regions for sequencing applications (Drogemoller et al. 2013). Last, NGS data utilization for 
U.I. Schwarz et al.

accurate prediction of novel, previously unseen haplotype structures or additions to known haplotypes through computational phasing methods is thought to be limited (Browning and Browning 2011; Lauschke and Ingelman-Sundberg 2016). Guidelines set by the CYP Allele Nomenclature Committee highlights caution toward novel sequence variation identified by NGS in CYP genes noting, "If a novel allele was discovered by NGS, confirmation by a second method such as Sanger sequencing or genotyping, is required. If a novel allele was discovered by Sanger sequencing, findings must be confirmed by repeat sequencing of a separate amplicon." Moreover, the 1000 Genomes Project (Abecasis et al. 2012) generated specific mask files that can aid researchers in the assessment of genomic regions considered accessible by short-read sequencing, also regarded as the "accessible genome" (ftp.1000genomes.ebi.ac .uk/vol1/ftp/phase1/analysis_results/supporting/ accessible_genome_masks). With regard to clinical diagnostics, some have suggested confirmation of discovered SNV through the simultaneous application of two different NGS platforms, also called orthogonal NGS, to further improve variant calling accuracy, because extensive Sanger sequencing is time consuming and also hampered by structural challenges within specific DNA regions (Chennagiri et al. 2016). To assist clinical laboratories with the validation of NGS platforms and interpretation and reporting of variants, the American College of Medical Genetics and Genomics (ACMG) and the Association for Molecular Pathology (AMP) have jointly published essential laboratory standards and guidelines (Rehm et al. 2013; Richards et al. 2015).

First results from extensive validation studies, including the above-introduced pharmacogenetics NGS panels (Gordon et al. 2016; Han et al. 2017; unpublished data), suggest that careful probe design in conjunction with advanced bioinformatics tools may overcome many of these limitations. For example, after repetitive refinements of the probe design, on average, high coverage of greater than $400 \times$ in $99.6 \%$ of selected genes and more than $99 \%$ accuracy has been reported for the ADME-PGx panels
(Han et al. 2017). In that study, NGS genotype data were compared to genotypes derived from HapMap (the International HapMap Consortium) reference control samples or drug-metabolizing enzymes and transporters (DMETs) Plus genotyping array data in hundreds of initially tested individuals. Similarly, a high level of performance and accuracy has been achieved for the PGRNseq panel with an average read coverage of almost $500 \times$ and over $99.8 \%$ concordance of NGS genotype data in two clinical cohorts of almost 200 patients also characterized using various genotyping platforms (Gordon et al. 2016). Concordance evaluation also included 32 diverse HapMap trios, each consisting of one adult and both parents, permitting Mendelian inheritance analysis as a suitable approach to screen for sites prone to false-positive calls by NGS. However, several inconsistencies were detected for CYP2A6 and CYP2D6 across multiple trios that were largely located in inaccessible regions with predicted low mappability. Similarly, discordant results were also observed for CYP2D6 with the ADME-PGx panels. Moreover, the highly polymorphic genes $H L A-B$ and $H L A-D Q B 3$ could not be considered for analysis of the PGRNseq panel, whereas these genes were not included in the ADME-PGx panels. This clearly shows the importance of tracking positions or genes with absent data or ambiguous calls, so that test limitations can be defined and alternative methods applied. Interestingly, whereas NGS is generally considered not suitable for the assessment of copy number variation (CNV), more recent findings suggest otherwise (Twist et al. 2016; Yang et al. 2016; Han et al. 2017; Iacocca et al. 2017). For example, the number of copies for GSTM1 and GSTT1, two genes known for common nonfunctional "null" alleles (gene deletion), could be predicted from the mean number of sequencing reads, the latter also proportional to copy number when determined by a PCR-based method (Han et al. 2017). Recent reports also indicated that CYP2D6 phenotypes can be reasonably well predicted from whole-exome and whole-genome sequences, including complex diplotypes with SNV, larger DNA rearrangements, and 
even gene deletion, duplication, and multiplication events for known haplotypes (Twist et al. 2016; Yang et al. 2016). Overall, despite the few cases of observed discordance in genes that are notorious for extensive homology or structural variations, these findings highlight the utility of targeted NGS-based panels in pharmacogenetic testing for research or diagnostic setting (Rasmussen-Torvik et al. 2017).

\section{PREDICTING FUNCTIONAL RELEVANCE USING BIOINFORMATICS TOOLS}

Beyond technical challenges for NGS approaches, the functional interpretation of sequencing results recognizing the enormous amount of rare, previously uncharacterized variation identified in pharmacogenes represents a significant obstacle in the clinical implementation of such pharmacogenetic sequencing platforms (Duzkale et al. 2013). Many different in silico prediction algorithms are available to categorize potentially protein-damaging effects of SNVs through scoring systems. These are generally based on the type of change (missense or splice site alterations), evolutionary sequence conservation (sorting intolerant from tolerant [SIFT]; Kumar et al. 2009), mutation taster (Adzhubei et al. 2010), structural stability (PolyPhen-2; Adzhubei et al. 2010), or represent composite algorithms integrating conservation metrics, protein-level effects, and regulatory information, among others (i.e., combined annotation dependent depletion [CADD]; Kircher et al. 2014). However, differences in outcome scores among these prediction tools have been previously reported concerning variants categorized as "deleterious" (Han et al. 2017), and some argue that these algorithms may not be wellsuited for the assessment of pharmacogenetics-related phenotypes as they have been derived from patient data to discern predictors of disease (Lauschke and Ingelman-Sundberg 2016). As shown in a recent study, actual functional consequences of novel rare variants in pharmacogenes such as CYP2C19, ABCB1, and SLCO1B1 were predicted with an accuracy of about $80 \%$ using the combined scores of SIFT, mutation taster, and CADD (Han et al. 2017). Thus, po- tentially functional SNPs can be missed or misinterpreted by in silico prediction as recently reported for the drug efflux transporter multidrug-resistant protein MRP4 (ABCC4) (Banerjee et al. 2016). Although two SNPs predicted to be functionally benign (V77I and C956S) resulted in severe impairment of MRP4 trafficking to the plasma membrane, two other SNVs predicted to be deleterious (C171G and G187W) showed substrate-dependent effects on MRP4 transport that may be explained by multiple pharmacologically distinct substrate-binding sites in the transporter. Similarly, substrate-dependent effects of SNVs have been also reported for members of the organic anion transporting polypeptides ([OATPs], SLC gene family) such as OATP1B3 (Letschert et al. 2004; Schwarz et al. 2011) and OATP1B1 (Tirona et al. 2001), showing the complex challenge of computational approaches in variant assessment. Last, accurate prediction of new haplotype structures or additions to known haplotypes through computational phasing methods is required to accurately predict phenotypes (Browning and Browning 2011; Snyder et al. 2015; Lauschke and Ingelman-Sundberg 2016). A representative example is $S L C O 1 B 1388 \mathrm{~A}>\mathrm{G}$ (rs2306283) or ${ }^{*} 1 B$, which is an allele shown to increase protein expression and uptake activity of the hepatic transporter OATP1B1 (Nies et al. 2013). The $S L C O 1 B 1^{*} 1 B$ allele has been associated with reduced drug exposure for the OATP1B1 substrates atovastatin and pravastatin (Mwinyi et al. 2004; Nies et al. 2013), improved lipidlowering response, and reduced statin-induced side effects (Donnelly et al. 2011; Rodrigues et al. 2011). However, these effects are largely reversed in the presence of SLCO1B1 521T>C (rs rs4149056) or *5 (combined SLCO1B1*15) (Tirona et al. 2001), a loss-off-function allele associated with reduced hepatic expression (Nies et al. 2013), increased statin plasma exposure (DeGorter et al. 2013; Nies et al. 2013), and a predictor of statin-associated myopathy (SEARCH Collaborative Group et al. 2008). Therefore, the incorporation of haplotype information in predictive algorithms is likely required to fully elucidate the cumulative effect of novel rare variants. 
U.I. Schwarz et al.

\section{IN VITRO AND IN VIVO FUNCTIONAL CHARACTERIZATION}

After computational analyses, suitable experimental and clinical validation approaches are needed to screen the variants for functional effects. Cell-based models have been commonly used to characterize functional effects of SNVs in metabolizing enzymes and drug transporters through enzymatic or transport activity assays with a specific substrate after transient or stable overexpression of the variant protein in comparison to a normal-function wild-type (Tirona et al. 2001; Kim 2002; Schwarz et al. 2011). Although this approach may allow the assessment of a small number of SNVs in clinically relevant or known target genes (Han et al. 2017), it is likely not feasible to be applied to all discovered variants considering the plethora of rare variation; 6750 rare putatively functional SNVs were recorded across 146 pharmacogenes among 7595 subjects (Kozyra et al. 2017). This underlines the necessity of alternative high-throughput screening methods, for example, using clustered regularly interspaced short palindromic repeats (CRISPR)/Cas9 libraries in cultured human cells (Shalem et al. 2014; Zhou et al. 2014). The genome editing CRISPR/Cas9 technology allows small, site-specific DNA changes such as SNVs, insertion/deletions (indels) as well as the deletion of larger genomic loci (i.e., exons) (Cong et al. 2013; Ran et al. 2013). As recently suggested (Lauschke and Ingelman-Sundberg 2016), SNV-containing guide RNAs (gRNAs) targeting ADME genes may be cloned into a lentiviral vector that is subsequently used to transfect most applicable cell lines for functional tests of thousands of pharmacogenetic variants to create specific libraries. However, initial screening and identification of such mutant cell clones represents a time-consuming, laborintensive, and costly requirement (Bell et al. 2014). Therefore, initiatives that help facilitate these large-scale experimental validation studies for pharmacogenomics research are essential such as the generation of gene-edited stem-cell clones for SNVs via the PGRN Pharmacogenomics iPSC Library and Service (PiLS) (www .pgrn.org/pgrn-pils-resource.html\#RFA1).
Underlying in vivo mechanisms of variable drug exposure or response because of variation in drug metabolizing enzymes or drug transporters have been traditionally evaluated in a small number of known variant and wild-type carriers after administration of specific probe drugs. For example, the influence of CYP2D6 genotype-predicted phenotypes on the metabolism of the prodrug codeine has been previously characterized in a classic PK study in healthy subjects (Kirchheiner et al. 2007), demonstrating absence of bioactivation to morphine in CYP2D6 poor metabolizers suggesting lack of effect. Whereas in vivo phenotyping with relevant probe drugs still represents a valuable strategy, sufficient numbers of variant carriers in the case of rare variants or specific probe drugs for pharmacogenes may not always be available. Consequently, information sharing through public repositories that capture the obtained cell-based and clinical information as well as collaboration among laboratories will aid in reducing the number of assessments needed and allow a more efficient and timely evaluation of the phenotypic significance of new genetic variation in pharmacogenes.

\section{DIAGNOSTIC TESTING AND CLINICAL IMPLEMENTATION}

Whereas thousands of pharmacogenetic biomarkers have been discovered in the past, only very few have been clinically implemented, in part because of the strict requirements for genetic testing. Prior to its clinical use, a genetic test must be evaluated for its analytic validity, clinical validity, and clinical utility as outlined by the ACCE framework (Sanderson et al. 2005; Burke 2014). Analytical validity relates to the test's ability to reliably and accurately measure the genotype of interest, which, as mentioned earlier, can be difficult for genes with complex genetic structure such as CYP2D6 (Gaedigk 2013). A test's ability to accurately detect or predict a patient's phenotype based on a genotype indicates its clinical validity. While current genotyping and sequencing technologies are sufficiently robust with respect to pharmacogenetic testing, defining the drug-effect phenotype has 
become more challenging, complicated by the fact that many drug effects are influenced by multiple variants in the same gene, some of which are rare, and by variants in multiple genes within a patient. Moreover, the variable prevalence of SNVs among different populations can confound the translation of pharmacogenetic traits (Zhou et al. 2017) as reported for genetic polymorphisms in CYP2C9 and VKORC1, determining a race-specific anticoagulant response to warfarin (Limdi et al. 2008). Moreover, in contrast to most Mendelian traits, drug-effect phenotypes are generally the composite of genetic as well as clinical (comorbidity) and environmental (drug interactions, diet) factors (DeGorter et al. 2012), thus the positive predictive value for pharmacogenetic tests can be low. Last, clinical utility evaluates whether the use of a genetic test leads to improved health outcomes via individualized drug dosing or treatment, and whether the test can identify patients at risk for drug toxicity (Lesko et al. 2010). The best outcomes that show effectiveness of a pharmacogenetic intervention in clinical care is widely debated, and may include a reduction in deleterious clinical events or overall health care costs. This is best illustrated for the anticoagulant warfarin, where intermediate outcomes such as out-of-range international normalized ratios (INRs) as well as clinically more robust hard outcomes such as severe bleeding are assessed. Although randomized controlled trials (RCTs) are commonly accepted as the gold standard for evidence to support the clinical utility of an intervention, they are very costly and may be challenging in study design because the benefit of pharmacogenetic interventions is largely restricted to an often small number of variant carriers (outliers). Moreover, feasibility of studies including hard end points such as adverse effects can be limited by their scarcity (i.e., very low bleeding rates for warfarin). While the application of the same genotype-based warfarin dosing algorithm in two different randomized controlled trials resulted in inconsistent findings for the primary outcome percent time in therapeutic range (Kimmel et al. 2013; Pirmohamed et al. 2013), this was likely caused by differences in the proportion of carriers with warfarin dose-predictive variant alleles as well as population-specific variants in AfricanAmericans that were not accounted for in the applied algorithm, among other reasons (Schwarz et al. 2014). Although it should be mentioned that a more recent randomized clinical trial, Genetics Informatics Trial (GIFT) with 1650 patients enrolled, showed that genotype-guided warfarin dosing improved the composite outcome of major bleeding, INR $>4$, venous thromboembolism, or death, when compared to a clinically guided dosing algorithm (Gage et al. 2017).

Other limitations may apply to studies that may be unethical of a drug that is known to cause serious life-threatening toxicities as in the case of the chemotherapeutic agent 5-fluorouracil in patients with DPYD poor metabolizer status. Consequently, evidence has to be derived from alternate data including case reports, family studies, retrospective case-control studies, systematic reviews and meta-analysis of individual patient data, allowing the linking of drug concentration or pharmacological effects to genetic variation (Meulendijks et al. 2015). Therefore, many pharmacogenetic tests are currently recommended and applied on the basis of alternative scientific evidence in the absence of RCTs.

\section{STATISTICAL CHALLENGES OF RARE GENETIC VARIATION}

Whereas large effects of common single variants on variable drug exposure or response in patients have been detected with various study designs and modest sample size, including GWAS (Takeuchi et al. 2009; Perera et al. 2013), much larger numbers of individuals as well as innovative study designs and statistical methods are required to study rare, mostly heterozygous SNVs affecting drug therapy outcomes, thereby making such efforts more costly and challenging (reviewed by Sagreiya et al. 2010; Lee et al. 2014; Zuk et al. 2014; Kaakinen et al. 2017). To improve statistical power, rare-variant association analyses (i.e., Burden test, variance-component tests, or combined omnibus tests) combine multiple variants in genetic regions of assumed rel- 
U.I. Schwarz et al.

evance using specific software packages such as PLINK (atgu.mgh.harvard.edu/plinkseq) (Purcell et al. 2007; Chang et al. 2015) or SKAT (www.hsph.harvard.edu/skat). To increase sample size, data from multiple studies/centers are often assessed through rare-variant meta-analysis strategies. The above-described eMERGEPGx multicenter project shows best these efforts in linking rare pharmacogenetic variation data from as many as 5000 patients with therapeutic outcomes derived from their electronic health records (eMERGE-PGx) (Rasmussen-Torvik et al. 2014; Bush et al. 2016), creating a research resource to test such rare variant associations, for example, between a group of stop-gain genetic variants and disease (Verma et al. 2016).

\section{CLINICAL IMPLEMENTATION OF PHARMACOGENETIC TESTS}

At present, pharmacogenetic testing remains largely confined to specialized laboratories and medical centers. Several barriers have been noted to hinder its widespread routine clinical use (reviewed in Relling and Evans 2015; Lauschke and Ingelman-Sundberg 2016; Dias et al. 2017). One obstacle is a lack of incentives for clinicians to conduct tests or implement procedures that might prevent adverse events. In addition, many health care systems do not provide reimbursement for this type of service. Another obstacle is insufficient knowledge of tests or clear guidelines on how to translate the pharmacogenetic genotypes into clinical action that can further discourage the acceptance by clinicians. This involves complex nomenclature systems such as the Human CYP Allele Nomenclature (www.pharmvar.org), unclear reporting standards, or disagreement with guidelines from professional societies, for example, concerning the drugs warfarin (Cavallari and Nutescu 2014) and clopidogrel (Chan et al. 2014), the latter commonly because of lack of RCTs demonstrating the benefit of pharmacogenetic testing compared to standard care and very limited data to suggest cost-effectiveness of pharmacogenetic testing. Another important consideration involves the availability of effective, alternative therapies for variant allele carriers at high risk or the ability to monitor therapeutic drug concentrations if nonstandard dose adjustments are made (for drugs with an established concentration-effect relationship). To facilitate clinical implementation, the CPIC regularly publishes detailed guidelines on how test results for clinically actionable, inherited pharmacogenetic variation should be reported and translated into clinical practice (Caudle et al. 2017). Cost and complexity of the computational approaches required to identify, annotate, and interpret genetic variants is another significant obstacle, specifically if NGS approaches are more widely used. Although an increasing number of bioinformatics tools for analyzing genetic variation are available, a substantial level of knowledge and manual interpretation is still required. Considering the potential relevance of rare variation, the challenge will be to catalog and annotate these variants in publicly available databases that can be updated such as PharmGKB, ClinGen, or ClinVar to be potentially associated with electronic health-care record systems linking genetic test results with evidence-based treatment decisions (Relling and Evans 2015). Other barriers include insufficient knowledge of prescribers as well as concern about incidental or secondary findings from genetic testing (Richards et al. 2015; Li et al. 2017). However, many of the ethics related concerns that surround diagnostic testing for disease-risk variants is less of concern in pharmacogenes, given their primary relevance to drug responsiveness (Relling and Evans 2015).

\section{CONCLUDING REMARKS}

Rare variation in drug metabolism and response genes comprises a yet unrecognized part in individual differences in drug therapy. NGS represents a promising new technology enabling fast, cost-efficient, and comprehensive interrogation of DNA sequences. Despite current limitations of NGS in pharmacogenes, the integration of such data into candidate genotyping approaches and consideration of largely rare, functional pharmacogenetic variation will allow a more precise prediction of individual drug 
phenotypes in patients and thus more adequate genotype-based dose adjustments.

\section{ACKNOWLEDGMENTS}

This work is supported by the Wolfe Medical Research Chair in Pharmacogenomics and the Canadian Institutes of Health Research, Drug Safety and Effectiveness Network (DSEN-PREVENT, FRN-117588), and Ontario Research Fund-Research Excellence Round 8.

\section{REFERENCES}

1000 Genomes Project Consortium; Abecasis GR, Auton A, Brooks LD, DePristo MA, Durbin RM, Handsaker RE, Kang HM, Marth GT, McVean GA. 2012. An integrated map of genetic variation from 1,092 human genomes. Nature 491: 56-65.

Adzhubei IA, Schmidt S, Peshkin L, Ramensky VE, Gerasimova A, Bork P, Kondrashov AS, Sunyaev SR. 2010. A method and server for predicting damaging missense mutations. Nat Methods 7: 248-249.

Altmuller J, Budde BS, Nurnberg P. 2014. Enrichment of target sequences for next-generation sequencing applications in research and diagnostics. Biol Chem 395: 231237.

Banerjee M, Marensi V, Conseil G, Le XC, Cole SP, Leslie EM. 2016. Polymorphic variants of MRP4/ABCC4 differentially modulate the transport of methylated arsenic metabolites and physiological organic anions. Biochem Pharmacol 120: 72-82.

Bell CC, Magor GW, Gillinder KR, Perkins AC. 2014. A high-throughput screening strategy for detecting CRISPR-Cas9 induced mutations using next-generation sequencing. BMC Genomics 15: 1002.

Biesecker LG, Green RC. 2014. Diagnostic clinical genome and exome sequencing. $N$ Engl J Med 370: 2418-2425.

Blanchard RL, Freimuth RR, Buck J, Weinshilboum RM, Coughtrie MW. 2004. A proposed nomenclature system for the cytosolic sulfotransferase (SULT) superfamily. Pharmacogenetics 14: 199-211.

Bosma PJ, Chowdhury JR, Bakker C, Gantla S, de Boer A, Oostra BA, Lindhout D, Tytgat GN, Jansen PL, Oude Elferink RP, et al. 1995. The genetic basis of the reduced expression of bilirubin UDP-glucuronosyltransferase 1 in Gilbert's syndrome. N Engl J Med 333: 1171-1175.

Browning SR, Browning BL. 2011. Haplotype phasing: Existing methods and new developments. Nat Rev Genet 12 703-714.

Burke W. 2014. Genetic tests: Clinical validity and clinical utility. Curr Protoc Hum Genet 81: 9.15.1-9.15.8.

Bush WS, Crosslin DR, Owusu-Obeng A, Wallace J, Almoguera B, Basford MA, Bielinski SJ, Carrell DS, Connolly JJ, Crawford D, et al. 2016. Genetic variation among 82 pharmacogenes: The PGRNseq data from the eMERGE network. Clin Pharmacol Ther 100: 160-169.
Caudle KE, Klein TE, Hoffman JM, Muller DJ, Whirl-Carrillo M, Gong L, McDonagh EM, Sangkuhl K, Thorn CF, Schwab M, et al. 2014. Incorporation of pharmacogenomics into routine clinical practice: The Clinical Pharmacogenetics Implementation Consortium (CPIC) guideline development process. Curr Drug Metab 15: 209-217.

Caudle KE, Dunnenberger HM, Freimuth RR, Peterson JF, Burlison JD, Whirl-Carrillo M, Scott SA, Rehm HL, Williams MS, Klein TE, et al. 2017. Standardizing terms for clinical pharmacogenetic test results: Consensus terms from the Clinical Pharmacogenetics Implementation Consortium (CPIC). Genet Med 19: 215-223.

Cavallari LH, Nutescu EA. 2014. Warfarin pharmacogenetics: To genotype or not to genotype, that is the question. Clin Pharmacol Ther 96: 22-24.

Chan NC, Eikelboom JW, Ginsberg JS, Lauw MN, Vanassche T, Weitz JI, Hirsh J. 2014. Role of phenotypic and genetic testing in managing clopidogrel therapy. Blood 124: 689-699.

Chang CC, Chow CC, Tellier LC, Vattikuti S, Purcell SM, Lee JJ. 2015. Second-generation PLINK: Rising to the challenge of larger and richer datasets. Gigascience 4: 7.

Chennagiri N, White EJ, Frieden A, Lopez E, Lieber DS, Nikiforov A, Ross T, Batorsky R, Hansen S, Lip V, et al. 2016. Orthogonal NGS for high throughput clinical diagnostics. Sci Rep 6: 24650.

Cong L, Ran FA, Cox D, Lin S, Barretto R, Habib N, Hsu PD, Wu X, Jiang W, Marraffini LA, et al. 2013. Multiplex genome engineering using CRISPR/Cas systems. Science 339: 819-823.

Cook I, Wang T, Falany CN, Leyh TS. 2013. High accuracy in silico sulfotransferase models. J Biol Chem 288: $34494-$ 34501.

Daly AK. 2010. Genome-wide association studies in pharmacogenomics. Nat Rev Genet 11: 241-246.

DeGorter MK, Kim RB. 2009. Hepatic drug transporters, old and new: Pharmacogenomics, drug response, and clinical relevance. Hepatology 50: 1014-1016.

DeGorter MK, Xia CQ, Yang JJ, Kim RB. 2012. Drug transporters in drug efficacy and toxicity. Annu Rev Pharmacol Toxicol 52: 249-273.

DeGorter MK, Tirona RG, Schwarz UI, Choi YH, Dresser GK, Suskin N, Myers K, Zou G, Iwuchukwu O, Wei WQ, et al. 2013. Clinical and pharmacogenetic predictors of circulating atorvastatin and rosuvastatin concentrations in routine clinical care. Circ Cardiovasc Genet 6: 400-408.

Dewey FE, Murray MF, Overton JD, Habegger L, Leader JB, Fetterolf SN, O’Dushlaine C, Van Hout CV, Staples J, Gonzaga-Jauregui C, et al. 2016. Distribution and clinical impact of functional variants in 50,726 whole-exome sequences from the DiscovEHR study. Science 354: aaf6814.

Dias MM, Sorich MJ, Rowland A, Wiese MD, McKinnon RA. 2017. The routine clinical use of pharmacogenetic tests: What it will require? Pharm Res 34: 1544-1550.

Donnelly LA, Doney AS, Tavendale R, Lang CC, Pearson ER, Colhoun HM, McCarthy MI, Hattersley AT, Morris AD, Palmer CN. 2011. Common nonsynonymous substitutions in SLCO1B1 predispose to statin intolerance in routinely treated individuals with type 2 diabetes: A goDARTS study. Clin Pharmacol Ther 89: 210-216. 


\section{U.I. Schwarz et al.}

Drogemoller BI, Wright GE, Niehaus DJ, Emsley R, Warnich L. 2013. Next-generation sequencing of pharmacogenes: A critical analysis focusing on schizophrenia treatment. Pharmacogenet Genomics 23: 666-674.

Dunnenberger HM, Crews KR, Hoffman JM, Caudle KE, Broeckel U, Howard SC, Hunkler RJ, Klein TE, Evans WE, Relling MV. 2015. Preemptive clinical pharmacogenetics implementation: Current programs in five US medical centers. Annu Rev Pharmacol Toxicol 55: 89-106.

Duzkale H, Shen J, McLaughlin H, Alfares A, Kelly MA, Pugh TJ, Funke BH, Rehm HL, Lebo MS. 2013. A systematic approach to assessing the clinical significance of genetic variants. Clin Genet 84: 453-463.

Ehmann F, Caneva L, Prasad K, Paulmichl M, Maliepaard M, Llerena A, Ingelman-Sundberg $\mathrm{M}$, Papaluca-Amati $\mathrm{M}$. 2015. Pharmacogenomic information in drug labels: European Medicines Agency perspective. Pharmacogenomics J 15: 201-210.

Franke RM, Gardner ER, Sparreboom A. 2010. Pharmacogenetics of drug transporters. Curr Pharm Des 16: 220 230.

Fujikura K, Ingelman-Sundberg M, Lauschke VM. 2015. Genetic variation in the human cytochrome P450 supergene family. Pharmacogenet Genomics 25: 584-594.

Gaedigk A. 2013. Complexities of CYP2D6 gene analysis and interpretation. Int Rev Psychiatry 25: 534-553.

Gage BF, Bass AR, Lin H, Woller SC, Stevens SM, Al-Hammadi N, Li J, Rodríguez T Jr, Miller JP, McMillin GA, et al. 2017. Effect of genotype-guided warfarin dosing on clin ical events and anticoagulation control among patients undergoing hip or knee arthroplasty: The GIFT Randomized Clinical Trial. JAMA 318: 1115-1124.

Gonzalez FJ. 1988. The molecular biology of cytochrome P450s. Pharmacol Rev 40: 243-288.

Gordon AS, Fulton RS, Qin X, Mardis ER, Nickerson DA, Scherer S. 2016. PGRNseq: A targeted capture sequencing panel for pharmacogenetic research and implementation. Pharmacogenet Genomics doi: 10.1097/FPC. 0000000000000202.

Guillemette C. 2003. Pharmacogenomics of human UDPglucuronosyltransferase enzymes. Pharmacogenomics J 3 : 136-158.

Han SM, Park J, Lee JH, Lee SS, Kim H, Han H, Kim Y, Yi S, Cho JY, Jang IJ, et al. 2017. Targeted next-generation sequencing for comprehensive genetic profiling of pharmacogenes. Clin Pharmacol Ther 101: 396-405.

Hayes JD, Flanagan JU, Jowsey IR. 2005. Glutathione transferases. Annu Rev Pharmacol Toxicol 45: 51-88.

Iacocca MA, Wang J, Dron JS, Robinson JF, McIntyre $\mathrm{AD}$ Cao H, Hegele RA. 2017. Use of next-generation sequencing to detect LDLR gene copy number variation in familial hypercholesterolemia. J Lipid Res 58: 2202-2209.

International Human Genome Sequencing Consortium. 2004. Finishing the euchromatic sequence of the human genome. Nature 431: 931-945.

James MO, Ambadapadi S. 2013. Interactions of cytosolic sulfotransferases with xenobiotics. Drug Metab Rev 45: 401-414.

Johnson JA, Gong L, Whirl-Carrillo M, Gage BF, Scott SA, Stein CM, Anderson JL, Kimmel SE, Lee MT, Pirmohamed M, et al. 2011. Clinical Pharmacogenetics Imple- mentation Consortium Guidelines for CYP2C9 and VKORC1 genotypes and warfarin dosing. Clin Pharmacol Ther 90: 625-629.

Johnson JA, Burkley BM, Langaee TY, Clare-Salzler MJ, Klein TE, Altman RB. 2012. Implementing personalized medicine: Development of a cost-effective customized pharmacogenetics genotyping array. Clin Pharmacol Ther 92: 437-439.

Johnson JA, Caudle KE, Gong L, Whirl-Carrillo M, Stein CM, Scott SA, Lee MT, Gage BF, Kimmel SE, Perera MA, et al. 2017. Clinical Pharmacogenetics Implementation Consortium (CPIC) Guideline for Pharmacogenetics-Guided Warfarin Dosing: 2017 Update. Clin Pharmacol Ther 102: 397-404.

Kaakinen M, Magi R, Fischer K, Heikkinen J, Järvelin MR, Morris AP, Prokopenko I. 2017. A rare-variant test for high-dimensional data. Eur J Hum Genet 25: 988-994.

Kim RB. 2002. MDR1 single nucleotide polymorphisms: Multiplicity of haplotypes and functional consequences. Pharmacogenetics 12: 425-427.

Kimmel SE, French B, Kasner SE, Johnson JA, Anderson JL, Gage BF, Rosenberg YD, Eby CS, Madigan RA, McBane RB, et al. 2013. A pharmacogenetic versus a clinical algorithm for warfarin dosing. N Engl J Med 369: 2283-2293.

Kircher M, Witten DM, Jain P, O'Roak BJ, Cooper GM, Shendure J. 2014. A general framework for estimating the relative pathogenicity of human genetic variants. Nat Genet 46: 310-315.

Kirchheiner J, Schmidt H, Tzvetkov M, Keulen JT, Lötsch J, Roots I, Brockmöller J. 2007. Pharmacokinetics of codeine and its metabolite morphine in ultra-rapid metabolizers due to CYP2D6 duplication. Pharmacogenomics J 7: 257-265.

Koboldt DC, Steinberg KM, Larson DE, Wilson RK, Mardis ER. 2013. The next-generation sequencing revolution and its impact on genomics. Cell 155: 27-38.

Kozyra M, Ingelman-Sundberg M, Lauschke VM. 2017. Rare genetic variants in cellular transporters, metabolic enzymes, and nuclear receptors can be important determinants of interindividual differences in drug response. $\mathrm{Ge}$ net Med 19: 20-29.

Kuehl P, Zhang J, Lin Y, Lamba J, Assem M, Schuetz J, Watkins PB, Daly A, Wrighton SA, Hall SD, et al. 2001. Sequence diversity in CYP3A promoters and characterization of the genetic basis of polymorphic CYP3A5 expression. Nat Genet 27: 383-391.

Kumar P, Henikoff S, Ng PC. 2009. Predicting the effects of coding non-synonymous variants on protein function using the SIFT algorithm. Nat Protoc 4: 1073-1081.

Lauschke VM, Ingelman-Sundberg M. 2016. Requirements for comprehensive pharmacogenetic genotyping platforms. Pharmacogenomics 17: 917-924.

Leckband SG, Kelsoe JR, Dunnenberger HM, George AL Jr, Tran E, Berger R, Müller DJ, Whirl-Carrillo M, Caudle KE, Pirmohamed M, et al. 2013. Clinical Pharmacogenetics Implementation Consortium guidelines for HLA-B genotype and carbamazepine dosing. Clin Pharmacol Ther 94: 324-328.

Lee S, Abecasis GR, Boehnke M, Lin X. 2014. Rare-variant association analysis: Study designs and statistical tests. Am J Hum Genet 95: 5-23. 
Lek M, Karczewski KJ, Minikel EV, Samocha KE, Banks E, Fennell T, O'Donnell-Luria AH, Ware JS, Hill AJ, Cummings $\mathrm{BB}$, et al. 2016. Analysis of protein-coding genetic variation in 60,706 humans. Nature 536: 285-291.

Lesko LJ, Zineh I, Huang SM. 2010. What is clinical utility and why should we care? Clin Pharmacol Ther 88: 729733.

Letschert K, Keppler D, Konig J. 2004. Mutations in the SLCO1B3 gene affecting the substrate specificity of the hepatocellular uptake transporter OATP1B3 (OATP8). Pharmacogenetics 14: 441-452.

Li MM, Datto M, Duncavage EJ, Kulkarni S, Lindeman NI, Roy S, Tsimberidou AM, Vnencak-Jones CL, Wolff DJ, Younes A, et al. 2017. Standards and guidelines for the interpretation and reporting of sequence variants in cancer: A joint consensus recommendation of the Association for Molecular Pathology, American Society of Clinical Oncology, and College of American Pathologists. J Mol Diagn 19: 4-23.

Limdi NA, Beasley TM, Crowley MR, Goldstein JA, Rieder MJ, Flockhart DA, Arnett DK, Acton RT, Liu N. 2008. VKORC1 polymorphisms, haplotypes and haplotype groups on warfarin dose among African-Americans and European-Americans. Pharmacogenomics 9: 1445-1458.

Mackenzie PI, Owens IS, Burchell B, Bock KW, Bairoch A, Bélanger A, Fournel-Gigleux S, Green M, Hum DW, Iyanagi T, et al. 1997. The UDP glycosyltransferase gene superfamily: Recommended nomenclature update based on evolutionary divergence. Pharmacogenetics 7: 255 269.

Madian AG, Wheeler HE, Jones RB, Dolan ME. 2012. Relating human genetic variation to variation in drug responses. Trends Genet 28: 487-495.

Mamanova L, Coffey AJ, Scott CE, Kozarewa I, Turner EH, Kumar A, Howard E, Shendure J, Turner DJ. 2010. Target-enrichment strategies for next-generation sequencing. Nat Methods 7: 111-118.

Mandelker D, Schmidt RJ, Ankala A, McDonald Gibson K, Bowser M, Sharma H, Duffy E, Hegde M, Santani A, Lebo M, et al. 2016. Navigating highly homologous genes in a molecular diagnostic setting: A resource for clinical nextgeneration sequencing. Genet Med 18: 1282-1289.

Martin MA, Hoffman JM, Freimuth RR, Klein TE, Dong BJ, Pirmohamed M, Hicks JK, Wilkinson MR, Haas DW, Kroetz DL, et al. 2014. Clinical Pharmacogenetics Implementation Consortium Guidelines for HLA-B Genotype and Abacavir Dosing: 2014 update. Clin Pharmacol Ther 95: 499-500

Meulendijks D, Henricks LM, Sonke GS, Deenen MJ, Froehlich TK, Amstutz U, Largiadèr CR, Jennings BA, Marinaki AM, Sanderson JD, et al. 2015. Clinical relevance of DPYD variants c.1679T $>\mathrm{G}, \mathrm{c} .1236 \mathrm{G}>\mathrm{A} / \mathrm{HapB} 3$, and c. $1601 \mathrm{G}>\mathrm{A}$ as predictors of severe fluoropyrimidine-associated toxicity: A systematic review and meta-analysis of individual patient data. Lancet Oncol 16: 1639-1650.

Motsinger-Reif AA, Jorgenson E, Relling MV, Kroetz DL, Weinshilboum R, Cox NJ, Roden DM. 2013. Genomewide association studies in pharmacogenomics: Successes and lessons. Pharmacogenet Genomics 23: 383-394.

Mwinyi J, Johne A, Bauer S, Roots I, Gerloff T. 2004. Evidence for inverse effects of OATP-C (SLC21A6) 5 and $1 \mathrm{~b}$ haplotypes on pravastatin kinetics. Clin Pharmacol Ther 75: 415-421

Nelson DR, Koymans L, Kamataki T, Stegeman JJ, Feyereisen R, Waxman DJ, Waterman MR, Gotoh O, Coon MJ, Estabrook RW, et al. 1996. P450 superfamily: Update on new sequences, gene mapping, accession numbers and nomenclature. Pharmacogenetics 6: 1-42.

Nelson DR, Zeldin DC, Hoffman SM, Maltais LJ, Wain HM, Nebert DW. 2004. Comparison of cytochrome P450 (CYP) genes from the mouse and human genomes, including nomenclature recommendations for genes, pseudogenes and alternative-splice variants. Pharmacogenetics 14: 1-18.

Nelson MR, Wegmann D, Ehm MG, Kessner D, St Jean P, Verzilli C, Shen J, Tang Z, Bacanu SA, Fraser D, et al. 2012. An abundance of rare functional variants in 202 drug target genes sequenced in 14,002 people. Science 337: 100-104.

Ng SB, Turner EH, Robertson PD, Flygare SD, Bigham AW, Lee C, Shaffer T, Wong M, Bhattacharjee A, Eichler EE, et al. 2009. Targeted capture and massively parallel sequencing of 12 human exomes. Nature 461: 272-276.

Nielsen R, Paul JS, Albrechtsen A, Song YS. 2011. Genotype and SNP calling from next-generation sequencing data. Nat Rev Genet 12: 443-451.

Nies AT, Koepsell H, Winter S, Burk O, Klein K, Kerb R, Zanger UM, Keppler D, Schwab M, Schaeffeler E. 2009. Expression of organic cation transporters OCT1 (SLC22A1) and OCT3 (SLC22A3) is affected by genetic factors and cholestasis in human liver. Hepatology 50: $1227-1240$.

Nies AT, Niemi M, Burk O, Winter S, Zanger UM, Stieger B, Schwab M, Schaeffeler E. 2013. Genetics is a major determinant of expression of the human hepatic uptake transporter OATP1B1, but not of OATP1B3 and OATP2B1. Genome Med 5: 1 .

Omiecinski CJ, Vanden Heuvel JP, Perdew GH, Peters JM. 2011. Xenobiotic metabolism, disposition, and regulation by receptors: From biochemical phenomenon to predictors of major toxicities. Toxicol Sci 120: S49-S75.

Pei B, Sisu C, Frankish A, Howald C, Habegger L, Mu XJ, Harte R, Balasubramanian S, Tanzer A, Diekhans M, et al. 2012. The GENCODE pseudogene resource. Genome Biol 13: R51.

Perera MA, Cavallari LH, Limdi NA, Gamazon ER, Konkashbaev A, Daneshjou R, Pluzhnikov A, Crawford DC, Wang J, Liu N, et al. 2013. Genetic variants associated with warfarin dose in African-American individuals: A genome-wide association study. Lancet 382: 790-796.

Pirmohamed M. 2001. Pharmacogenetics and pharmacogenomics. Br J Clin Pharmacol 52: 345-347.

Pirmohamed M, Burnside G, Eriksson N, Jorgensen AL, Toh $\mathrm{CH}$, Nicholson T, Kesteven P, Christersson C, Wahlström B, Stafberg C, et al. 2013. A randomized trial of genotypeguided dosing of warfarin. N Engl J Med 369: 2294-2303.

Purcell S, Neale B, Todd-Brown K, Thomas L, Ferreira MA, Bender D, Maller J, Sklar P, de Bakker PI, Daly MJ, et al. 2007. PLINK: A tool set for whole-genome association and population-based linkage analyses. Am J Hum Genet 81: 559-575

Ramsey LB, Johnson SG, Caudle KE, Haidar CE, Voora D, Wilke RA, Maxwell WD, McLeod HL, Krauss RM, Roden 


\section{U.I. Schwarz et al.}

DM, et al. 2014. The clinical pharmacogenetics implementation consortium guideline for SLCO1B1 and simvastatin-induced myopathy: 2014 update. Clin Pharmacol Ther 96: 423-428.

Ran FA, Hsu PD, Wright J, Agarwala V, Scott DA, Zhang F. 2013. Genome engineering using the CRISPR-Cas9 system. Nat Protoc 8: 2281-2308.

Rao Y, Hoffmann E, Zia M, Bodin L, Zeman M, Sellers EM, Tyndale RF. 2000. Duplications and defects in the CYP2A6 gene: Identification, genotyping, and in vivo effects on smoking. Mol Pharmacol 58: 747-755.

Rasmussen-Torvik LJ, Stallings SC, Gordon AS, Almoguera B, Basford MA, Bielinski SJ, Bratbar A, Briliant MH, Carrell DS, Connolly JJ, et al. 2014. Design and anticipated outcomes of the eMERGE-PGx project: A multicenter pilot for preemptive pharmacogenomics in electronic health record systems. Clin Pharmacol Ther 96: 482-489.

Rasmussen-Torvik LJ, Almoguera B, Doheny KF, Freimuth RR, Gordon AS, Hakonarson H, Hawkins JB, Husami A Ivacic LC, Kullo IJ, et al. 2017. Concordance between research sequencing and clinical pharmacogenetic genotyping in the eMERGE-PGx Study. J Mol Diagn 19: 561566.

Rehm HL, Bale SJ, Bayrak-Toydemir P, Berg JS, Brown KK, Deignan JL, Freiz MJ, Funke BH, Hegde MR, Lyon E, et al. 2013. ACMG clinical laboratory standards for next-generation sequencing. Genet Med 15: 733-747.

Relling MV, Evans WE. 2015. Pharmacogenomics in the clinic. Nature 526: 343-350.

Relling MV, Gardner EE, Sandborn WJ, Schmiegelow K, Pui $\mathrm{CH}$, Yee SW, Stein CM, Carrillo M, Evans WE, Klein TE, et al. 2011. Clinical Pharmacogenetics Implementation Consortium guidelines for thiopurine methyltransferase genotype and thiopurine dosing. Clin Pharmacol Ther 89: 387-391.

Relling MV, Gardner EE, Sandborn WJ, Schmiegelow K, Pui $\mathrm{CH}$, Yee SW, Stein CM, Carrillo M, Evans WE, Hicks JK, et al. 2013. Clinical pharmacogenetics implementation consortium guidelines for thiopurine methyltransferase genotype and thiopurine dosing: 2013 update. Clin Pharmacol Ther 93: 324-325.

Richards S, Aziz N, Bale S, Bick D, Das S, Gastier-Foster J, Grody WW, Hegde M, Lyon E, Spector E, et al. 2015. Standards and guidelines for the interpretation of sequence variants: A joint consensus recommendation of the American College of Medical Genetics and Genomics and the Association for Molecular Pathology. Genet Med 17: 405-424.

Rodrigues AC, Perin PM, Purim SG, Silbiger VN, Genvigir FD, Willrich MA, Arazi SS, Luchessi AD, Hirata MH, Bernik MM, et al. 2011. Pharmacogenetics of OATP transporters reveals that SLCO1B1 c. $388 \mathrm{~A}>\mathrm{G}$ variant is determinant of increased atorvastatin response. Int J Mol Sci 12: 5815-5827.

Sagreiya H, Berube C, Wen A, Ramakrishnan R, Mir A, Hamilton A, Altman RB. 2010. Extending and evaluating a warfarin dosing algorithm that includes CYP4F2 and pooled rare variants of CYP2C9. Pharmacogenet Genomics 20: 407-413.

Saito Y, Stamp LK, Caudle KE, Hershfield MS, McDonagh EM, Callaghan JT, Tassaneeyakul W, Mushiroda T, Kamatani N, Goldspiel BR, et al. 2016. Clinical Pharmaco- genetics Implementation Consortium (CPIC) guidelines for human leukocyte antigen B (HLA-B) genotype and allopurinol dosing: 2015 update. Clin Pharmacol Ther 99: 36-37.

Sanderson S, Zimmern R, Kroese M, Higgins J, Patch C, Emery J. 2005. How can the evaluation of genetic tests be enhanced? Lessons learned from the ACCE framework and evaluating genetic tests in the United Kingdom. Genet Med 7: 495-500.

Sanger F, Nicklen S, Coulson AR. 1977. DNA sequencing with chain-terminating inhibitors. Proc Natl Acad Sci 74: 5463-5467.

Schwarz UI, Meyer zu Schwabedissen HE, Tirona RG, Suzuki A, Leake BF, Mokrab Y, Mizuguchi K, Ho RH, Kim RB. 2011. Identification of novel functional organic anion-transporting polypeptide 1B3 polymorphisms and assessment of substrate specificity. Pharmacogenet Genomics 21: 103-114.

Schwarz UI, Kim RB, Tirona RG. 2014. Genotype-guided dosing of vitamin $\mathrm{K}$ antagonists. $N$ Engl J Med 370: 1761-1762.

Scott SA, Sangkuhl K, Gardner EE, Stein CM, Hulot JS, Johnson JA, Roden DM, Klein TE, Shuldiner AR; Clinical Pharmacogenetics Implementation Consortium. 2011. Clinical Pharmacogenetics Implementation Consortium guidelines for cytochrome P450-2C19 (CYP2C19) genotype and clopidogrel therapy. Clin Pharmacol Ther 90: 328-332.

Scott SA, Sangkuhl K, Stein CM, Hulot JS, Mega JL, Roden DM, Klein TE, Sabatine MS, Johnson JA, Shuldiner AR, et al. 2013. Clinical Pharmacogenetics Implementation Consortium guidelines for CYP2C19 genotype and clopidogrel therapy: 2013 update. Clin Pharmacol Ther 94: 317-323.

SEARCH Collaborative Group, Link E, Parish S, Armitage J, Bowman L, Heath S, Matsuda F, Gut I, Lathrop M, Collins R. 2008. SLCO1B1 variants and statin-induced myopathyA genomewide study. N Engl J Med 359: 789-799.

Shalem O, Sanjana NE, Hartenian E, Shi X, Scott DA, Mikkelson T, Heckl D, Ebert BL, Root DE, Doench JG, et al. 2014. Genome-scale CRISPR-Cas9 knockout screening in human cells. Science 343: 84-87.

Sim SC, Kacevska M, Ingelman-Sundberg M. 2013. Pharmacogenomics of drug-metabolizing enzymes: A recent update on clinical implications and endogenous effects. Pharmacogenomics J 13: 1-11.

Snyder MW, Adey A, Kitzman JO, Shendure J. 2015. Haplotype-resolved genome sequencing: Experimental methods and applications. Nat Rev Genet 16: 344-358.

Takeuchi F, McGinnis R, Bourgeois S, Barnes C, Eriksson N, Soranzo N, Whittaker P, Ranganath V, Kumanduri V, McLaren W, et al. 2009. A genome-wide association study confirms VKORC1, CYP2C9, and CYP4F2 as principal genetic determinants of warfarin dose. PLoS Genet 5: e1000433.

Tennessen JA, Bigham AW, O'Connor TD, Fu W, Kenny EE, Gravel S, McGee S, Do R, Liu X, Jun G, et al. 2012. Evolution and functional impact of rare coding variation from deep sequencing of human exomes. Science 337: 64-69.

Tirona RG, Leake BF, Merino G, Kim RB. 2001. Polymorphisms in OATP-C: Identification of multiple allelic var- 
iants associated with altered transport activity among European- and African-Americans. J Biol Chem 276: 35669-35675.

The MHC Sequencing Consortium. 1999. Complete sequence and gene map of a human major histocompatibility complex. Nature 401: 921-923.

Twist GP, Gaedigk A, Miller JP, Farrow EG, Willig LK, Dinwiddie DL, Petrikin JE, Soden SE, Herd S, Gibson M, et al. 2016. Constellation: A tool for rapid, automated phenotype assignment of a highly polymorphic pharmacogene, CYP2D6, from whole-genome sequences. NPJ Genom Med 1: 15007.

Vanakker OM, De Paepe A. 2013. Pharmacogenomics in children: Advantages and challenges of next generation sequencing applications. Int J Pediatr 2013: 136524.

Verma A, Verma SS, Pendergrass SA, Crawford DC, Crosslin DR, Kuivaniemi H, Bush WS, Bradford Y, Kullo I, Bielinski SJ, et al. 2016. eMERGE Phenome-Wide Association Study (PheWAS) identifies clinical associations and pleiotropy for stop-gain variants. BMC Med Genomics 9(Suppl 1): 32

Wang D, Guo Y, Wrighton SA, Cooke GE, Sadee W. 2011. Intronic polymorphism in CYP3A4 affects hepatic ex- pression and response to statin drugs. Pharmacogenomics J 11: 274-286.

Yang W, Wu G, Broeckel U, Smith CA, Turner V, Haidar CE, Wang S, Carter R, Karol SE, Neale G, et al. 2016. Comparison of genome sequencing and clinical genotyping for pharmacogenes. Clin Pharmacol Ther 100: 380-388.

Yoon JK, Ahn J, Kim HS, Han SM, Jang H, Lee MG, Lee JH, Bang D. 2015. microDuMIP: Target-enrichment technique for microarray-based duplex molecular inversion probes. Nucleic Acids Res 43: e28.

Zhou Y, Zhu S, Cai C, Yuan P, Li C, Huang Y, Wei W. 2014 High-throughput screening of a CRISPR/Cas9 library for functional genomics in human cells. Nature 509: 487491.

Zhou Y, Ingelman-Sundberg M, Lauschke VM. 2017. Worldwide distribution of cytochrome P450 alleles: A meta-analysis of population-scale sequencing projects. Clin Pharmacol Ther 102: 688-700.

Zuk O, Schaffner SF, Samocha K, Do R, Hechter E, Kathiresan S, Daly MJ, Neale BM, Sunyaev SR, Lander ES. 2014. Searching for missing heritability: Designing rare variant association studies. Proc Natl Acad Sci 111: E455-E464. 


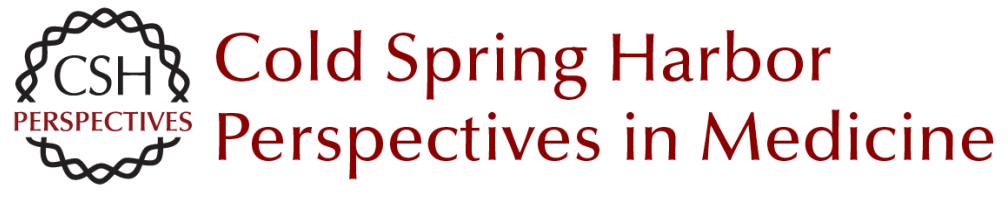

\section{The Role of Next-Generation Sequencing in Pharmacogenetics and Pharmacogenomics}

Ute I. Schwarz, Markus Gulilat and Richard B. Kim

Cold Spring Harb Perspect Med 2019; doi: 10.1101/cshperspect.a033027 originally published online May 29, 2018

\section{Subject Collection Next-Generation Sequencing in Medicine}

Next-Generation Sequencing Technologies

W. Richard McCombie, John D. McPherson and

Elaine R. Mardis

The Impact of Next-Generation Sequencing on

Cancer Genomics: From Discovery to Clinic Elaine R. Mardis

Next-Generation Sequencing in Autism Spectrum

Disorder Stephan J. Sanders

Sequencing in High Definition Drives a Changing

Worldview of the Epigenome Emily Hodges

Whole-Genome Sequencing in Cancer

Eric Y. Zhao, Martin Jones and Steven J.M. Jones

High Throughput Sequencing and Assessing

Disease Risk

Shannon M. Rego and Michael P. Snyder

Clinical Versus Research Sequencing

Yuriy Shevchenko and Sherri Bale
Single-Cell Applications of Next-Generation
Sequencing Naishitha Anaparthy, Yu-Jui Ho, Luciano Martelotto, et al.

Future Promises and Concerns of Ubiquitous Next-Generation Sequencing W. Richard McCombie and John D. McPherson Next-Generation Sequencing Strategies
Shawn E. Levy and Braden E. Boone

Characterizing the Cancer Genome in Blood Sarah-Jane Dawson

The Role of Next-Generation Sequencing in Pharmacogenetics and Pharmacogenomics Ute I. Schwarz, Markus Gulilat and Richard B. Kim

The Use of Next-Generation Sequencing for Research and Diagnostics for Intellectual

Disability

Ricardo Harripaul, Abdul Noor, Muhammad Ayub, et al.

Next-Generation Sequencing and the Return of

Results

Bartha Maria Knoppers, Minh Thu Nguyen, Karine

Sénécal, et al.

For additional articles in this collection, see http://perspectivesinmedicine.cshlp.org/cgi/collection/ 